\title{
ADAPTING AN ABSORPTION BEAMLINE TO PERFORM XRD COMBINED WITH XAFS EXPERIMENTS
}

Sousa, M. F. ${ }^{\text {*; }}$; Figueroa, S. J. A. ${ }^{2}$; Espíndola, A. M. ${ }^{2}$; Eleotério, M. S. ${ }^{2}$, Levinsky, A. S. ${ }^{2}$; Maurício, J. ${ }^{2}$; Zambello, F. ${ }^{2}$; Fonseca, V. ${ }^{2}$

1Universidade Federal do Ceará, Departamento de Física, Laboratório de Raios X, Fortaleza, Ceará, Brasil

2 Centro Nacional de Pesquisa em Energia e Materiais, Laboratório de Luz Síncrotron, Campinas, São Paulo, Brasil

*souldefalcao@gmail.com

During the summer scholarship program in the Brazilian Synchrotron Light Laboratory, the XAFS2 beamline was adapted to perform X-ray Diffraction measurement. This beamline instrumentation allows us to open a new possibilities on the usual XAFS experiments, which is specially useful for combine the techniques to obtaining structural information on short and long range order. We explore both techniques performing in situ studies with a capillary micro-reactor [1] at the same time the hydrogen desorption was measured with mass spectroscopy on metal hydrides (MgCo compounds) during a thermal treatment under helium atmosphere. The possibility of changing the experimental setup between XAFS and XRD within minutes a complete description of the material changes in various operating conditions, were obtained. Indeed, this is a very promising set up combination to explore catalysts or functional materials, which increase the research possibilities of the beamline.

[1] S.J.A Figueroa, D. Gibson, T. Mairs, et al., J. Appl. Cryst., 2013, 46, 1523-1527 